\title{
Editor's Page
}

In this final issue of volume 8 , we have devoted our entire report section to a symposium dealing with the coastline of the Maritime Provinces of Canada. This work was originally based on a field conference organized by the Coastal Commission of the International Geographical Union which met in Halifax at a technical session, and included field excursions to numerous local points of interest in harmony with the subjects of the speakers. The authors of the symposium deserve considerable praise for the manner in which they have directed interested workers to the field problems, and for the very fine sumnaries of work to date on these problems in their respective areas. It takes very little stressing to outline the significance of these studies in view of the severe aspects of coastal pollution, erosion, habitation, construction and recreation. More far-reaching implications may yet be at hand: the possible harnessing of tidal power and its attendant problems of erosion, siltation, and environmental change; the effects of altered drainage pattern and deltaic growth; and the shifting of major sediment patterns due to altered topography both ashore and at sea. The principles demonstrated by the symposium authors will be the first line of attack, or defence, in solving the physical problems of the coastal zone, and this battle is now joined. We have no need to wait for long passages of time, because these processes act quickly - not in $10^{6}$ years.

Another symposium on coastal features was held by the Department of Geology at State University of New York, Binghampton, N.Y. This dealt primarily with coastal geomorphology, and some of its participants also assisted on the earlier meetings of the year in the Maritime Provinces. The director of the Binghampton Symposium, Donald R. Coates, in introducing his meeting concluded with the following statement:...."Beaches and coasts have become a favorite locale for a wide range of man's activities, and this extraordinary fragile environment deserves all the scientific attention and analysis that can be mustered". Without question, both symposia are critical, topical, and vital.

The terrain analysis division of the Geological survey of Canada has made numerous inroads to problems on the longest coastline in the world - 45,000 miles of it. Some of the studies are based in areas of permafrost and this in itself is a major erosional issue in the far north. But less unique will be the continued application of pleistocene geology on land, conventional profiling studies on the beaches and landward portions of the coast, and more intensive quantitative investigations on the movement of sediments on and off the shore. These studies moving seaward must incorporate those aspects of hydrodynamics as they apply to offshore sedimentation, including erosion and sedimentary transport. A crossing of disciplines into the field of the physicist will be needed as more and more surveying in the adjacent submarine portion of the coast reveals the existence of sedimentary nodal patterns. The increased application of spectral analysis is foreseen to explain the movement of sand waves within a major wave carrier, or to understand the alternating bands of fine and coarse sediments lying just offshore. As in so many cases, we must rely on a team of specialists to embrace the problem, particularly if its scope is vast; or we must educate the devotee in his particular field and arm him with sufficient knowledge of the peripheral fields that he may be easily conversant with such expertise and can apply himself singly to his problem. In some cases the problem is resolved by circumstances in others by availability. In the near future, even, we may not have the opportunity to make the choice, and anything may be thrown into the breach. Therefore it is now time for many of our municipalities to gear for a full scale assault on coastal problems, either by teams or by individuals. Many countries have begun, but others are far behind. The frequency of the coastal symposia clearly indicates the accelerating anxiety over this important aspect of our lives.

Under our Current Research section we have given examples of research in sedimentary geology undertaken by the Department of Geology at Acadia University, Wolfville, Nova Scotia. The studies cover both the unconsolidated sediments and those in lithified form. All but the joint research project with Atlantic Geoscience Centre are graduate programs leading to the M.Sc. degree. Two of these will be granted this spring: one to D.J. Macdonald, and the other to P.D. McCulloch. Also in this section we have given two publisher's accounts of new books. Unfortunately we have not seen THE MEDITERRANEAN SEA by D.J. Stanley, but ORIGIN OF SEDIMENTARY ROCKS by Blatt, Middleton and Murray has been studied, and found to be a very good text indeed. This will be the subject of a book review in a forthcoming number of this magazine. At a late date we observed the new COASTAL GEOMORPHOLOGY, edited by Donald R. Coates (see above).

In closing this volume we wish to give thanks to our many contributors, and to the National Research Council of Canada for providing a grant which, together with subscriptions, permits us to publish without fear of financial strain. It is the policy of MARITIME SEDIMENTS to publish all contributions without cost to the authors. We accept no advertisements for fee, but will publish notices and accounts of new materials, meetings, courses and programs. We hope to have your continued participation, to which is offered our final thanks in this volume. 